\title{
(a)
}

\section{Planning ahead, the only solution to sustain agricultural systems}

\section{Editorial}

Along with the ever-increasing world population and the pressure on land resources and increasing human ecological footprints, it's time to change the way humans look at how to use nature. In the theory of humanism, everything starts from humans and ends with humans, and there is no truth superior to man. Modern agriculture is based on the principle of reductionism. In this view, based on the mechanical world-view that roots in Newton's philosophical mechanics, the world is viewed as a group of isolated phenomena that have no living, interconnected nature. In this attitude, man and his interests are priorities (the culmination of this thought appears in the Descartes School of Thought: I think, then I am). In this vision, the association of objects and phenomena is not organic and interacting, and it is not considered comprehensively for the understanding of relations and phenomena. Based on this idea, soil is not considered as a living and dynamic entity, which contains a collection of living organisms and biological, physical and chemical interactions, but rather as a mere non-living physical environment, which humans are allowed to manipulate its structure and function by means of using machinery, fertilizers, chemical pesticides and other inputs. In this view, that reflects the basic principles of agricultural economics, natural resources have always been valued in the right way as other sources such as inputs and labor, and in this way, the values and functions of life and the ecology of nature is far from over. The result of such a view was the human invasion of natural resources and the reduction of ecological reserves.

So that the level of human exploitation of the Earth in 1985 was 1.5 times higher than Earth's capacity. An ecological deficit occurs when the ecological footprint of the population is more than the earth bio capacity and we have left this point. It is in these circumstances that the demand of the growing population of the world to receive goods and services, and in particular land (to meet human needs for all food and clothing), will outpace the potential of ecosystems for renewing. Today, the world's population has devoted almost $50 \%$ of the habitat lands to agriculture. About 77 percent of these 50 percent is dedicated to livestock, accounting for less than one-fifth of the world's calories. However, the share of crops (about $23 \%$ of the agricultural land area) in supplying global calories is more than $80 \%$ ( http://ourwordindata. org). From a general ecology point of view, plants are the first trophic level in each food chain, while herbivores are the second trophic level in the food chains of terrestrial ecosystems. Based on the second law of thermodynamics (law of Increased Entropy), the energy transfer coefficient per step from the ecosystem to the next step is around $10 \%$. This phenomenon happens in any system. Over time, usable energy will eventually give way to dissipated energy. Or in other words, over time the entropy state in each system will continuously increase. This means that one of the ways to reduce the pressure on the earth to supply calories is to try to produce more calories at higher levels of the food chain.

Undoubtedly, if all the people on earth are vegetarian, the capacity of the earth will increase for acceptance of the world's population. Whether this can be done is another question, but theories show this. The important point here is that, in order to improve the earth state and

\author{
Volume 8 Issue 3 - 2018
}

\author{
Behnam Kamkar \\ Department of Agronomy, Gorgan University of Agricultural \\ Sciences and Natural Resources (GUASNR), Iran
} Correspondence: Behnam Kamkar, Professor, Department
of Agronomy, Gorgan University of Agricultural Sciences and
Natural Resources (GUASNR), Iran, P.O. Box: 49 189-43464, Tel,
+98-9I I 2734I53, 98-17-32427060, Email kamkar@gau.ac.ir

Received: May 25, 2018| Published: May 28, 2018

reducing the threat to food security, we need to shift our focus from the question "how much we eat" to the question of "what we eat". Now, a question arises: What is the solution to these challenges? It seems that human beings in the production of food must come to the theory of "thinking globally, acting locally." Land use planning must be carried out on different scales, and the duties of nations must be cleared in providing food to the world. In fact, land use planning is a smart design, in which production is adapted to regional capabilities. Nowadays, agriculture is not, in many cases, compatible with regional capabilities. For example, the crops with high water consumption are produced in many arid and semi-arid regions of the world, while the ability of these areas to be abandoned for the production of high-value and drought-resistant plants has been forgotten. For example, sugar beets and sugar cane are still cultivated in some regions of Iran, which, according to studies, are among the high-risk Drought-prone areas of the world. Meanwhile, valuable products such as saffron, dates, grapes, barberry, pomegranate, olive, etc. can be produced in these areas. This illustrated example highlights an important point that for moving towards sustainable agriculture, "the design of ecosystems," will be the only option. The answer to the question "what to eat" will be given only when we have the right image of our country's capabilities and believe that all components of an agricultural ecosystem are interconnected and interact and affect each other. This kind of look at the production from the ecological point of view, along with the belief that the earth has its own laws and we are obliged to respect the laws of the earth, will save man in the future. In this way, humans will be only part of a system, and their survival will depend on the survival of other components of the ecosystem. This is a holistic philosophy that is against the thinking of humanism. Both methods of production and consumption patterns seem to change to achieve sustainability. That is, we need to know what we should eat and how to produce it. The answer to these two questions is summarized in a stratrgy: Planning, Planning, and Panning.

\section{Acknowledgments}

None.

\section{Conflict of interest}

The authors declared there is no conflict of interest. 